\title{
Forest Fuel Inventory in 5 and 9-Year-Old Acacia Mangium Plantations
}

\begin{abstract}
This study was conducted to determine the fuel components on forest floor of two different age stands and to estimate the fuel loading of the various fuel components. This study was carried out at Bukit Tarek Forest Reserve, Hulu Selangor, Selangor Darul Ehsan, at two stand age of $\langle$ I $>$ Acacia mangium $</$ I $>$ of 5 and 9-year-old. Fuel components of downed woody material and duff were sampled along transects lines. Shrubs, litter, herbaceous and small trees $(<3 \mathrm{~m}$ height) were sampled from quadratic plots. The results showed that the forest fuel components in both stands were similar but not in term of their fuel loading. The 5 yearold stand showed $23.31 \mathrm{Mg}$ haG $<$ SUP $>1</$ SUP $>$ of total fuel (downed woody material, litter and herbaceous), $1.73 \mathrm{~cm}$ of duff depth, 37,030 stem haG $<$ SUP $>1</ \mathrm{SUP}>$ of shrubs density and 2,175 tree $h a G<S U P>1</ S U P>$ of small trees. The 9 year-old stand showed $17.42 \mathrm{Mg}$ haG $<$ SUP $>1</$ SUP $>$ of forest fuel, $3.03 \mathrm{~cm}$ of duff depth, 39,151 stem haG $<$ SUP $>1</ S U P>$ shrubs density and 3,515 tree haG $<$ SUP $>1</$ SUP $>$ of small trees. Downed woody material made up of 89 and $74 \%$ of the total fuel weight for 5 year and 9 -year-old stands, respectively. Comparison between two different age stands, showed that 5 year old stand has higher quantity of downed woody materials than 9 year-old stand with 20.66 and $12.82 \mathrm{Mg}$ haG $<$ SUP $>1</$ SUP $>$, respectively. Based on diameter class interval, the weight of downed woody material, diameter class of 0-7.6 $\mathrm{cm}$ were higher compared to diameter class of $>7.6$ $\mathrm{cm}$. The fuel weight for 0-7.6 $\mathrm{cm}$ diameter class was 12.48 and $9.94 \mathrm{Mg} \mathrm{haG}<\mathrm{SUP}>1</ \mathrm{SUP}\rangle$ for 5 and 9-year-old stands, respectively. Statistical analysis showed that the loading of downed woody material on 5-year-old stand was significantly greater than the 9 year-old stand. However, litter loading was greater on the 9-year-old stand than the 5-year-old stand. The study concludes that in terms of fuel loading, 5-year-old stand has higher fire risk than 9year-old stand. This is due to the silviculture activities in the 5-year old stand
\end{abstract}

Keyword: Forest fuel, forest plantation, Acacia mangium, Malaysia 